\title{
Supporting Information \\ Continuous-flow synthesis of the azo pigment yellow 14 using a three-stream micromixing process
}

\author{
Fa-Jun Wang, Jin-Pei Huang, Jian-Hong $\mathrm{Xu}^{*}$ \\ The State Key Laboratory of Chemical Engineering, Department of Chemical \\ Engineering, Tsinghua University, Beijing 100084, China \\ * Corresponding author: \\ E-mail address: xujianhong@tsinghua.edu.cn
}

\section{The transparency numbers calculation}

According to the definitions and calculation methods in the literature ${ }^{1}$.The definitions of the transparency number $(\mathrm{T})$ are that the amount of pigments dispersion which has to be painted on an area of $1 \mathrm{~m}^{2}$ black paper to achieve a CIELab colour difference of one unit.

The formula as follows:

$$
\mathrm{T}=\frac{M}{S \times \Delta E}
$$

M: the amount of the pigment painted on black paper

S: the area of black paper

$\triangle \mathrm{E}$ : the CIELab difference between an imprinted and nonimprinted standardised sheet of black paper. 
Table S1 The transparency numbers based on the CIELab colour using a sheet of black paper

\begin{tabular}{|c|c|c|c|}
\hline Sample & $\mathrm{M} / \mathrm{S}$ & $\triangle \mathrm{E}$ & $\mathrm{T}$ \\
\hline $1 \#$ & & 10.32 & 2.94 \\
\hline $2 \#$ & 30.30 & 10.38 & 2.92 \\
\hline $3 \#$ & & 10.69 & 2.83 \\
\hline Yellow14 standard & & 20.57 & 1.47 \\
\hline
\end{tabular}

\section{The thermogravimetric curve of the pigments}

The thermogravimetric curves of the pigments synthesized by the three-stream mixing process and the Yellow 14 standard were measured. Figure S1 shows that the same thermogravimetric curve are obtained. The decomposition temperatures of both pigment products synthesized by different processes are approximately $339^{\circ} \mathrm{C}$.

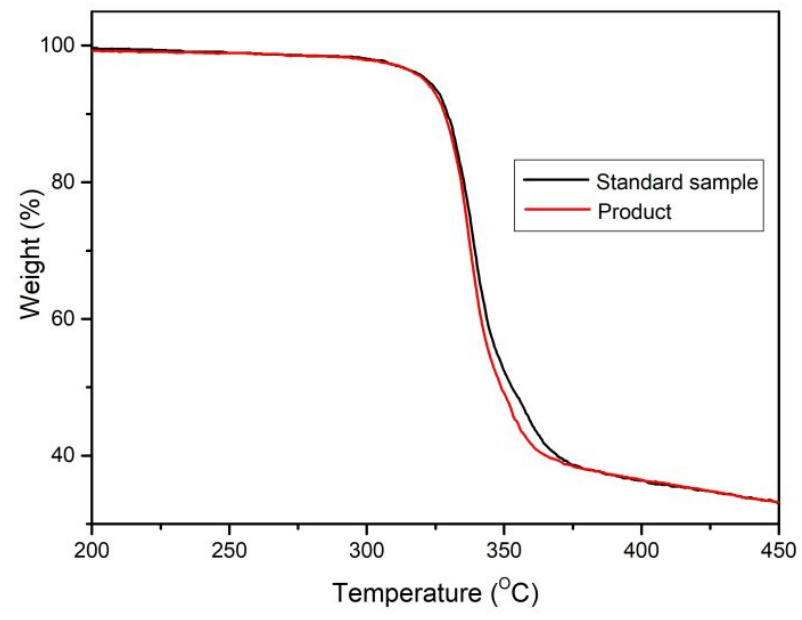

Figure S1 The thermogravimetric curve of the pigments

\section{The IR Spectral of pigment products and Yellow 14 standard}

The IR Spectral of the pigments synthesized by three-stream mixing process and Yellow 14 
standard were measured. Figure S2 shows that the IR Spectral of both pigment products synthesized by different processes are exactly the same.

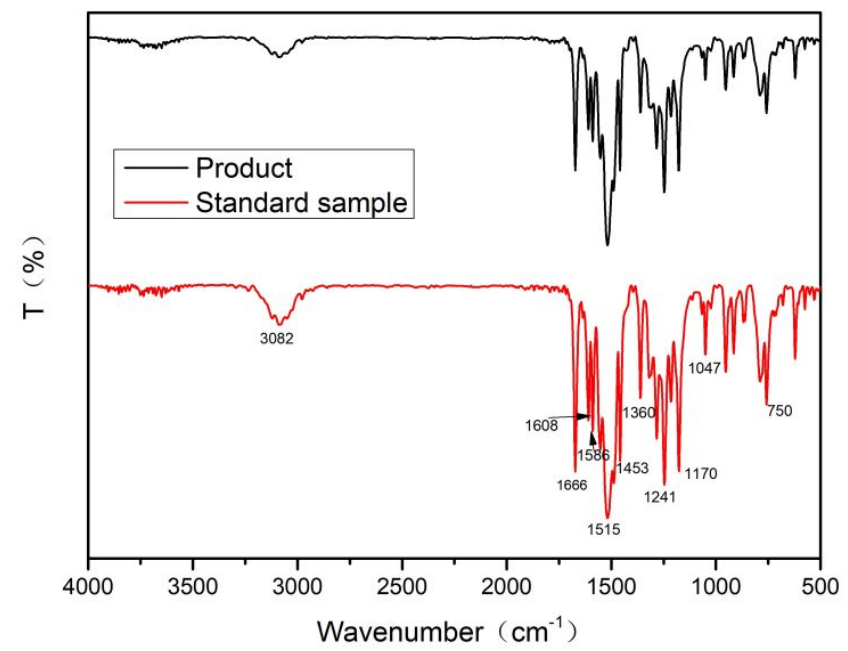

Figure S2 The IR Spectral of pigment products and Yellow 14 standard

\section{Reference:}

1 Pennemann, H.; Forster, S.; Kinkel. Improvement of Dye Properties of the Azo Pigment Yellow 12 Using a Micromixer-Based Process. Org. Process Res. Dev. 2005, 9, 188-192. 